\title{
Manifestações e protestos no Brasil: uma resenha
}

GOHN, Maria da Glória. Manifestos e protestos no Brasil: correntes e contracorrentes na atualidade. São Paulo: Cortez Editora, 2017.

Anna Kristyna Araújo da Silva Barbosa ${ }^{1}$

O debate acerca dos movimentos sociais teve, de certo modo, relevância nos espaços acadêmicos e nos espaços públicos de uma maneira geral, mas entre os anos de 2013-2016 esse debate ganhou ainda mais proeminência, sobretudo devido às novas configurações que esses movimentos foram tomando. O livro Manifestações e protestos no Brasil: correntes e contracorrentes na atualidade, de Maria da Glória Gohn, aqui resenhado, tem por objetivo analisar as manifestações e protestos no Brasil desde junho de 2013 até o impeachment em 2016 observando seus três momentos e suas alterações. Destacados e categorizados pela autora como novíssimos movimentos sociais, são eles: Movimento Passe Livre (MPL), Vem Pra Rua (VPR) e o Movimento Brasil Livre (MBL). Ademais, traça considerações sobre as ocupações em forma de protestos que ocorreram nas escolas de rede públicas de ensino médio e técnico entre 2015 e 2016.

$\mathrm{Na}$ introdução a autora apresenta o referencial teórico traçando algumas considerações sobre algumas categorias - consideradas como centrais para entender as manifestações e protestos analisados - que serão usadas ao longo do livro como: novo, povo, massa, multidão, sociedade, indignação e cultura política. Além disso, apresenta a identidade dos sujeitos coletivos nas ruas. Nesse tópico, Gohn caracteriza os movimentos sociais e os divide em três grupos: os clássicos, que são os movimentos organizados de forma tradicional, com identidades rígidas, apoiado pelos sindicatos que tinha/tem por objetivo a reivindicação de melhorias na vida e nas condições de trabalho da classe dos trabalhadores operando de forma centralizada nos ideias e no envolvimento com as suas bases; os novos, que são movimentos que foram criados no final da década de 1970 e tendo como objetivo a luta pela identidade cultural, ficando seus objetivos pela participação e inclusão das minorias - mulher, negro, índio, pobre etc.; por último, os novíssimos que são os movimentos que surgiram na atualidade que apresentam características bem diversificadas quanto à pauta, valores, ideologias e etc.

\footnotetext{
${ }^{1}$ Mestranda em Sociologia pela Universidade Federal de Pernambuco. E-mail: annakristyna07@gmail.com
} 
No primeiro capítulo da primeira parte intitulado Os Novíssimos Sujeitos Coletivos nas Ruas - 2013-2016, a autora analisa três movimentos de expressão dentro do que ela caracteriza como movimentos novíssimos e apresenta um panorama geral sobre as megamanifestações nesse período. O Movimento Passe Livre (MPL), o Vem Pra Rua (VPR) e o Movimento Brasil Livre (MBL) são elencados pela autora por serem expressivos no cenário político. O MPL foi criado em 2014 e apresenta inúmeras novidades no que tange a características dos movimentos sociais. Esse movimento se difere tanto na performance, como nas cores das roupas usadas, por se apresentar como autônomo e sem representatividade característica do princípio da horizontalidade. No período de 2013 o MPL tinha como objetivo central a oposição ao aumento das tarifas dos transportes sendo o grande diferencialo trabalho de base realizado pelo movimento em regiões da periferia. Em 2015, nas manifestações de março, o movimento perde o protagonismo e em janeiro de 2016 regressam às ruas como coadjuvantes, tendo como principal bandeira o impeachment da presidente Dilma Rousseff.

O VPR foi criado em 2014 e teve sua agenda construída gradativamente. Fundado por dois engenheiros - Rogério Chequer e Colin Butterfield - que tinham suas demandas centradas em "matrizes discursivas liberais modernas em que a gestão empresarial e a governança corporativa são modelos a seguir, em toda organização social, mesmo que de voluntários." (p. 37-38). O movimento amparou-se muito nos usos das redes sociais para articulação e divulgação dos protestos nas ruas. O movimento foi o idealizador dos panelaços que ocorreram em protesto à corrupção e como forma de mostrar indignação frente a política econômica do Brasil. O VPR apresentou vários slogans para os atos, além de outros nomes anteriores como "Basta" e "Desafio Basta". Ainda no ano de sua criação realizou duas manifestações em outubro, no período eleitoral, ganhando a simpatia da população por ir contra o lado "sujo" da política, ganhando relativa projeção nacional e internacional. Em 2015, após a eleição da presidente Dilma Rousseff e certo tempo depois de reformulações estratégicas, o VPR volta e realiza novas manifestações em conjunto com outros movimentos, a exemplo, do MBL. Diferentemente do MPL, o VPR apresentava uma estrutura interna que permitia uma representatividade, pois tinha um Conselho com sete líderes que tomavam decisões sobre os rumos e demandas das manifestações, bem como regras de permanência ou exclusão do movimento. O VPR 
sofreu várias críticas pela mídia por não deixar evidente as formas, fontes e valores dos financiamentos recebidos.

O MBL, também criado em 2014, nasceu com objetivo principal de ser "contra tudo que está aí", tendo como líder-fundador Kim Kataguiri. O movimento se coloca no meandro entre liberalismo e o neoconservadorismo. O MBL apresenta uma pauta contra vários direitos sociais e diferentemente do VPR e MPL atua na política lançando vários candidatos via vários partidos políticos, a exemplo de Fernando Holiday que foi eleito pelos Democratas (DEM) com o apoio do movimento. O MBL cria vários slogans como "Fora PT", "Fora Dilma”, tem fortes influências dos conservadores Burke e Ortega y Gasset que passam a aparecer nos cartazes nas manifestações promovidas pelo movimento. Além disso, o MBL apoiou o projeto Escola sem Partido e atos contra as ocupações das escolas.

No segundo capítulo a autora aborda o ciclo de protesto de 2013 tomando como base a concepção de ciclo usada por Tarrow. Segundo Maria Gloria Gohn, o ciclo de manifestações e protestos apresentam três momentos. O primeiro momento intitulado de Manifestações e Protestos: Novíssimos Atores em cena em junho de 2013 que contempla as manifestações ocorridas ao longo de junho de 2013 tendo dois grupos como expoentes: os automistas e os socialistas utópicos. Gohn mostra o aspecto importante devido ao surgimento de uma agenda política diferente e uma cultura política incomum. A bandeira das manifestações se volta no combate contra a corrupção, a reivindicação por melhorias nos serviços públicos e para o campo moral. A esse respeito Andrade (2016) explana bem a relação do moralismo e discurso contra corrupção que aparecem nas manifestações entre 2013 e 2015 um ponto em consonância com a abordagem de Gohn é o caráter moral que essas manifestações vão assumido. O segundo momento abordado por Gohn acontece em 2014: Surgimento de Contracorrentes nos "Novíssimos" aponta o surgimento de outros movimentos dentro dos novíssimos, a exemplo do Vem Pra Rua (VPR), o Movimento Brasil Livre (MBL), o Nas Ruas e os Revoltados Online que apresentam divergências entre si (o primeiro liberal, o segundo neoconservador e os dois últimos de caráter reacionário). Gohn argumenta que surge um novo momento dentro do ciclo de manifestações, pois há uma renovação da cultura política e desses sujeitos sociopolíticos que tem o impeachment como pauta convergente dessa nova agenda. Em 
paralelo a esse cenário, a Operação Lava Jato sustenta a pauta anticorrupção proposta pelos movimentos, que termina essa fase tendo a eleição presidencial sendo o principal foco. O terceiro momento é intitulado: A multidão retorna às Ruas - 15 de março. Nesse momento a autora aponta que há um acirramento político entre duas correntes de protesto: a antigolpe (composto pelos movimentos clássicos e parte dos novos) e a pró-impeachment (composto pelos novíssimos). Nesse momento também há a negação no campo da política partidária de certos partidos, milhares de pessoas saem às ruas, o combate à corrupção se intensifica e após as eleições presidenciais, com a vitória de Dilma Rousseff, a divisão na sociedade em dois lados é evidenciada.

Em 2016, no ano do impeachment, há um confronto entre os clássicos, novos e novíssimos movimentos e um acirramento na divisão política. Os clássicos se posicionam contra o corte de direitos sociais e trabalhistas e as reformas do governo de Michel Temer.

O país ficou divido, a política entrou na agenda do cotidiano do cidadão comum. Os movimentos sociais passaram a ser "a voz das ruas", balizadores da força social na luta por mudança ou pela conservação do status quo. Os dois blocos clamavam em nome da democracia. Para um dos lados, o impeachment seria sinônimo de golpe e atentado ao Estado de direito. Para o outro, o impeachment era a mudança necessária para restaurar e combater a corrupção e salvaguardar a democracia. (p. 25).

A novidade da contribuição do livro Manifestações e protestos no Brasil está contida na segunda parte, Lutas e Movimentos pela Educação, em que a autora aborda os protestos e manifestações no campo educacional ocorridos em 2015 e 2016 focalizando as ocupações nas escolas de ensino médio e técnico (São Paulo, Rio de Janeiro e Goiás) e o movimento contra o Projeto Escola sem Partido. A autora destaca as sete ciclos dos movimentos dos estudantes a partir de um levantamento histórico. O primeiro surge a partir dos anos de 1960 e o sétimo nas ocupações realizadas pelos estudantes de escolas de ensino médio e técnico a partir do ano de 2015. A autora considera que o diferencial está no protagonismo assumido pelos estudantes do ensino médio, visto que ao longo da história dos movimentos educacionais e da militância estudantil a nível nacional, esse protagonismo era dos estudantes de ensino superior. A autora também argumenta que a organização, a performance, a estratégia de ocupação, bem como o repertório das demandas apresentadas pelos alunos nas ocupações constituiu um grande diferencial 
desse ciclo de manifestações. Segundo Maria Gloria Gohn os movimentos educacionais ocorridos nesse período apresentam características similares aos movimentos de junho de 2013 como a horizontalidade, a falta de lideranças e os princípios libertários, além do intenso uso das redes sociais. A autora aborda também as ocupações de escolas que ocorreram pelo Brasil no ano de 2016 que tiveram como objetivo a oposição contra a Medida Provisória da Reforma do Ensino Médio e contra a PEC 241, que foram aprovadas apesar das ocupações contrárias. Esses atos ocorrem em outubro de 2016 em meio a preparação para o Exame Nacional do Ensino Médio (ENEM). As ocupações realizadas pelos estudantes tiveram apoio dos professores da rede pública e privada que, juntamente com os estudantes, cobravam do governo o debate sobre as reformas antes de sua implementação.

A autora termina o livro abordando as manifestações de repúdio ao Projeto Escola sem Partido idealizado por Miguel Nagib que posteriormente virou o projeto de Lei $\mathrm{n}$. 193/2016 de autoria do senador Magno Malta. O projeto foi proposto em 11 estados do Brasil, provocando inúmeros debates acerca do tema dando origem ao Movimento contra Escola sem Partido. A autora apresenta algumas críticas ao projeto, de personalidades como a filósofa Marilena Chauí e Frei Beto.

A partir das observações feitas, a autora conclui que as manifestações e os protestos ocorridos entre junho de 2013 e o impeachment de 2016 evidenciaram os diversos movimentos sociais da atualidade e suas características, demandas, cultura política, estratégias e perfis político-ideológico que compuseram uma rede de correntes e contracorrentes subdividas em três momentos. Além disso, as manifestações ocorridas nesse período mostram a fragilidade da democracia e a perda do protagonismo por parte dos clássicos e novos movimentos que, mesmo se juntando em frentes e voltando as ruas, não conseguiram recuperar o espaço tomado pelos novíssimos. A autora argumenta que mesmo ocorrendo de forma paralela etendo conexões com algumas propostas de alguns novíssimos, os movimentos educacionais não foram recepcionados da mesma forma pela população.

O livro Manifestações e protestos no Brasil: correntes e contracorrentes na atualidade traz como contribuição as alterações significativas ocorridas nos movimentos soci- 
ais no Brasil nos últimos anos, pontuando de forma significava as diferenças entre cada corrente e contracorrente além de apresentar as transformações históricas ocorridas. 0 fato de focalizar nas lutas no campo educacional também foi diferencial do livro e da autora, sendo capaz de transmitir aos leitores uma quantidade imensa de informações e reflexões a respeito da temática no Brasil de forma clara e fundamentada. Desse modo recomendamos a leitura.

\section{Referências}

ANDRADE, Ana Olívia Costa de. 'Contra tudo isto que está aí': moralismo e política nas manifestações 'Fora Dilma' em João Pessoa. João Pessoa: Xeroca!, 2017. 